Int. J. Dev. Biol. 64: 445-452 (2020)

https://doi.org/10.1387/ijdb.180145op

\title{
Measuring functional brain recovery in regenerating planarians by assessing the behavioral response to the cholinergic compound cytisine
}

\author{
ONÉ R. PAGÁN* , DEBRA L. BAKER, SEAN DEATS, MARY O'BRIEN, ROCHELLE DYMOND \\ and GABRIELLA DEMICHELE \\ Department of Biology, West Chester University West Chester, PA, USA
}

\begin{abstract}
Planarians are traditional model invertebrates in regeneration and developmental biology research that also display a variety of quantifiable behaviors useful to screen for pharmacologically active compounds. One such behavior is the expression of seizure-like movements (pSLMs) induced by a variety of substances. Previous work from our laboratory showed that cocaine, but not nicotine, induced pSLMs in intact but not decapitated planarians. Interestingly, as decapitated planarians regenerated their heads, they gradually recovered their sensitivity to cocaine. These results suggested a method to assess planarian brain regeneration and a possible way of identifying compounds that could enhance or hold back brain regeneration. In the present work, we demonstrate that the cholinergic agent cytisine is a suitable reference compound to apply our method. Cytisine induces pSLMs in a concentration-dependent manner in intact (but not decapitated) planarians of the species Girardia tigrina. Based on our data, we developed a behavioral protocol to assess planarian brain regeneration over time. We tested this method to measure the effect of ethanol on G. tigrina's brain regeneration. We found that ethanol slows down the rate of planarian brain regeneration in a concentration-dependent manner, consistently with data from other research groups that tested ethanol effects on planarian brain regeneration using different behavioral protocols. Thus, here we establish a general method using cytisine-induced pSLMs as an indicator of brain regeneration in planarians, a method that shows potential for assessing the effect of pharmacologically active compounds in this process.
\end{abstract}

KEY WORDS: brain, regeneration, pharmacology, cytisine, planaria

\section{Introduction}

Several species of freshwater planarians are established model invertebrates in regeneration and developmental biology research (Cebrià et al., 2002, 2018, 2019; Ivankovic et al., 2019; Gentile et al., 2011; Li et al., 2015). One of the most distinct advantages of the planarian model system is that many planarians species display a remarkable ability shared by very few other organisms: the capacity for complete (and correct) regeneration of their nervous system upon injury or even full decapitation (Cebrià, 2007, 2008, 2019; Gentile et al., 2011; Owlarn and Bartscherer, 2016; Ross et al., 2017; Umesono et al., 2011). The nervous system in these organisms is controlled by a bona fide brain that displays many features in common with vertebrate brains. For example, genes related to the planarian central nervous system are highly conserved across phyla (Cebrià et al., 2002a,b; Mineta, et al., 2003; Umesono and Agata, 2009), and planarian neurons are similar to vertebrate nerve cells in terms of morphology and other cytological characteristics (Pagán, 2014; Sarnat and Netsky, 1985, 2002). Additionally, many flatworm species possess many well-characterized neurotransmitter systems (Buttarelli et al., 2008; Nakazawa et al., 2003; Ribeiro et al., 2005). These facts established the usefulness of the freshwater planarian as an animal model for the study of

Abbreviations used in this paper: APW, artificial pond water; pSLM, planarian seizurelike movement.

*Address correspondence to: Oné R. Pagán. Department of Biology, West Chester University, 750 S Church St, West Chester, PA 19383, USA. Tel: +1-610-4362165. E-mail: opagan@wcupa.edu -Web: https://www.wcupa.edu/sciences-mathematics/biology/oPagan/default.aspx (ID) https://orcid.org/0000-0001-8232-7346

Supplementary Material (two videos) for this paper is available at: https://doi.org/10.1387/ijdb.180145op

Submitted: 22 May, 2018; Accepted: 9 June, 2020.

ISSN: Online 1696-3547, Print 0214-6282

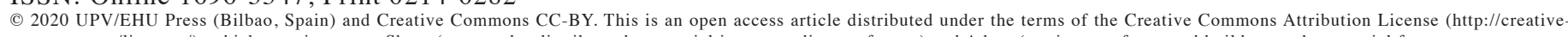

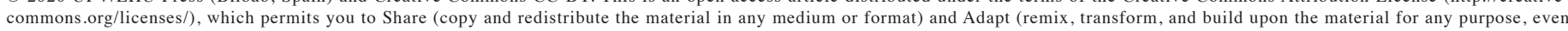

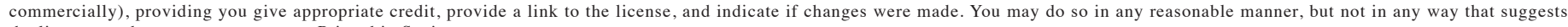
the licensor endorses you or your use. Printed in Spain 


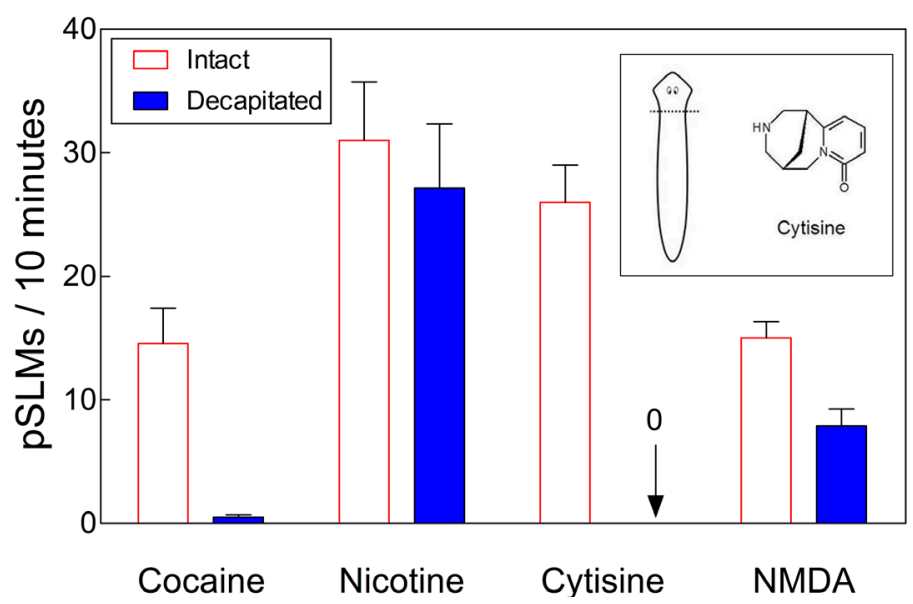

Fig. 1. Compounds capable of inducing at least 15 seizure-like movements (pSLM)/10 minutes in intact or decapitated planarians at a concentration of $\mathbf{1} \mathbf{~ m M}$, as indicated. $N=6-19$ worms per bar (see text and Table 1). The error bars represent the standard error of the mean. Inset: Outline of a planarian showing the point of decapitation (dotted line); drawing courtesy of Mr. Alexis G. Pagán), and cytisine structure.

nervous systems in general (Pagán, 2014, 2017, 2019; Pellettieri, 2019; Roberts-Galbraith et al., 2015, 2016; Ross et al., 2017; Umesono et al., 2011).

The contributions of planarians to biological research are not limited to the neurosciences and to developmental/regeneration biology. Since the mid-1970s planarians are proving themselves as relevant animal models in pharmacology and toxicology, on account of the aforementioned neurochemical similarities with vertebrates (Hagstrom et al., 2015, 2016, 2019; Ireland et al., 2020; Pagán, 2014, 2017, 2019; Poirier et al., 2019; Raffa and Rawls, 2008; Wu and Li, 2018; Zhang et al., 2019). Another reason for their usefulness in this regard is that planarians display a diverse repertoire of drug-induced quantifiable behaviors amenable to pharmacological manipulation. One of these behaviors is the planarian seizure like movement (pSLM). This behavioral response has also been referred to as a C-like hyperkinesia (Palladini et al., 1996; Pagán et al., 2008) and is expressed as a series of sudden contractions/twitches of the anterior section while the tail is usually anchored to the bottom of the container, as opposed to the passive gliding that these animals normally display (please see Supplementary Video 1). pSLMs are easily quantified visually, are concentration-dependent, and have been used to document the behavioral effects of a variety of psychoactive agents, including cocaine, nicotine, and opiates, among other compounds (Bach et al., 2016; Bezerra da Silva et al., 2016; Pagán et al., 2008, 2012, 2013, 2015; Raffa and Rawls, 2008; Ramakrishnan and Desaer, 2011; Ramakrishnan et al., 2013; Ramoz et al., 2012, Rawls et al., 2009, 2010, 2011; Tallarida et al., 2014).

Previous work from our laboratory showed that nicotine is able to induce pSLMs in intact or decapitated planarians. In contrast, cocaine-induced pSLMs are only expressed in intact planarians; if a planarian brain is surgically disrupted in any way, the ability of cocaine to induce pSLMs is significantly reduced, or upon decapitation, completely eliminated (Pagán et al., 2013). Furthermore, we also showed that decapitated planarians gradually recovered their sensitivity to cocaine as their central nervous system regenerated (Pagán et al., 2013). This recovery of cocaine sensitivity correlated closely with anatomical observations of the timeline of planarian brain regeneration using histochemical methods (Cebrià, 2007; Fraguas et al., 2012). Our results suggested a general method of behaviorally assessing the regeneration of the planarian brain, and also suggested a way to identify substances capable of delaying or enhancing planarian brain regeneration. Cocaine, being a controlled substance, is an impractical reference compound in this regard. Therefore, we performed a limited screening of various substances capable of inducing pSLMs only in planarians with intact brains (Table 1). Out of 19 substances tested, we identified

\section{TABLE 1}

\section{SCREEN OF COMPOUNDS SELECTED FOR THEIR ABILITY TO INDUCE PLANARIAN SEIZURE-LIKE MOVEMENTS (p-SLM) AT A CONCENTRATION OF 1 mM IN INTACT OR DECAPITATED PLANARIANS}

\begin{tabular}{|c|c|c|c|c|}
\hline Compound & Main pharmacological activity & $\begin{array}{c}\text { pSLM/10 minutes induced by } 1 \mathrm{mM} \\
( \pm \text { SEM) - Intact planarians }\end{array}$ & $\begin{array}{l}\text { pSLM/10 minutes induced by } 1 \mathrm{mM} \\
( \pm \mathrm{SEM}) \text { - Decapitated planarians }\end{array}$ & Reference \\
\hline Cocaine & Dopamine transporter antagonist / Local anesthetic & $14.6 \pm 2.8 ; N=12$ & $0.5 \pm 0.2 ; N=8$ & This work \\
\hline Nicotine & Cholinergic agonist & $31.0 \pm 4.7 ; \mathrm{N}=7$ & $27.1 \pm 5.2 ; N=7$ & This work \\
\hline Cytisine & Cholinergic partial agonist & $26.0 \pm 3.0 ; N=12$ & $0 \pm 0 ; N=6$ & This work \\
\hline N-methyl-D-aspartic acid & Glutamatergic agonist & $15.0 \pm 1.3 ; \mathrm{N}=19$ & $7.9 \pm 1.4 ; \mathrm{N}=19$ & This work \\
\hline Amphetamine & Dopamine transporter antagonist & $1.4 \pm 0.5 ; N=8$ & - & Pagán et al., 2012 \\
\hline Dopamine & Dopaminergic agonist & $4.0 \pm 2.0 ; N=13$ & - & This work \\
\hline Lidocaine & Local anesthetic & $3.9 \pm 2.0 ; N=5$ & - & Pagán et al., 2013 \\
\hline Procaine & Local anesthetic & $8.8 \pm 0.9 ; N=6$ & - & This work \\
\hline Procainamide & Antiarrhythmic agent / Local anesthetic & $6.4 \pm 2.1 ; N=9$ & - & This work \\
\hline Carbamylcholine & Cholinergic agonist & $5.8 \pm 3.3 ; N=4$ & - & This work \\
\hline Dihydro-beta-erythroidine & Cholinergic antagonist & $4.8 \pm 1.4 ; N=4$ & - & This work \\
\hline Cotinine & Cholinergic antagonist & $0.3 \pm 0.3 ; N=4$ & - & Bach et al., 2016 \\
\hline d-Tubocurarine & Cholinergic antagonist & $7.5 \pm 1.5 ; N=8$ & - & Pagán et al., 2015 \\
\hline L-glutamic acid & Glutamatergic agonist / Natural amino acid & $11.8 \pm 1.5 ; \mathrm{N}=10$ & - & Pagán et al., 2012 \\
\hline D-glutamic acid & Glutamatergic agonist / Natural amino acid & $10.9 \pm 1.9 ; N=10$ & - & Pagán et al., 2012 \\
\hline Serotonin & Serotonergic agonist & $1.0 \pm 0.6 ; N=3$ & - & This work \\
\hline Caffeine & Adenosine receptor antagonist & $0.5 \pm 0.5 ; N=2$ & - & This work \\
\hline Picrotoxin & GABA antagonist & $2.3 \pm 2.2 ; N=4$ & - & This work \\
\hline L-alanine & Natural amino acid & $3.7 \pm 1.2 ; N=3$ & - & This work \\
\hline
\end{tabular}


cytisine, a cholinergic compound (Fig. 1), as a concentrationdependent pSLMs inducer in intact-but not decapitated-planarians. Based on our data, we developed a behavioral method to assess planarian brain regeneration as described above. We validated this method by measuring the effect of ethanol on the planarian Girardia tigrina's brain regeneration.

\section{Results}

\section{Candidate compounds to study pSMLs in planarians}

Table 1 shows a series of compounds of various pharmacological specificities, that we tested at a concentration of $1 \mathrm{mM}$ for their ability to induce pSLMs, as we reasoned that this is a physiologically-relevant concentration. We had two main criteriafor selecting a specific candidate compound for further study: (1) that at $1 \mathrm{mM}$ concentration the candidate chemical would be capable of inducing at least 15 pSLMs in ten minutes in intact planarians, just like cocaine did (as reported in Pagán et al., 2013), and (2) that said candidate compound at the same concentration (1 mM) would be unable to induce pSLMs in decapitated planarians. We found four candidate compounds that fit the first criterion: cocaine, nicotine, cytisine (a cholinergic agonist), and NMDA (N-methyl-D-aspartic acid), a glutamatergic agonist (Table 1, Fig. 1). In the cases of cocaine and nicotine, our results replicated our previous findings (Pagán et al., 2013). Of the two previously untested compounds, only cytisine fulfilled the second criterion, as decapitation completely abolished its pSLM-inducing ability, while decapitation decreased the NMDA-induced pSLMs by roughly $50 \%$ (Table 1, Fig. 1). Thus, we chose cytisine as our candidate compound to assess planarian brain regeneration. In this work, we used cytisine to measure the delay of the reacquisition of behavioral responses by ethanol in regenerating worms. Ethanol has been found to delay the recovery of locomotor behavior in decapitated planarians of the species Schmidtea mediterranea (Lowe et al., 2015).

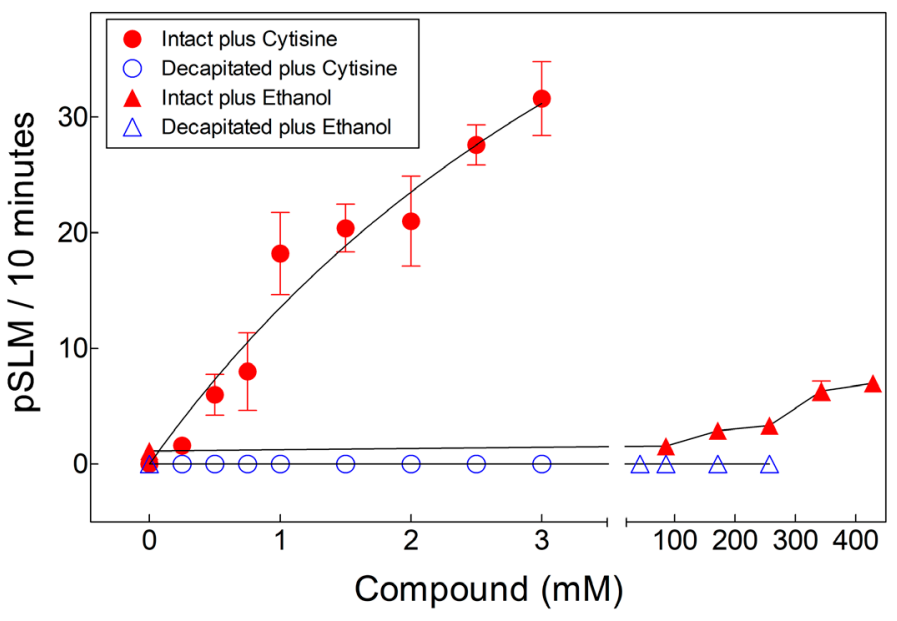

Fig. 2. Cytisine and ethanol induced seizure-like movements in intact (but not decapitated) planarians in a concentration-dependent manner, as indicated. $N=4-8$ worms per symbol. The error bars represent the standard error of the mean. Whenever error bars are not showing, it means that they are smaller than the symbol size.

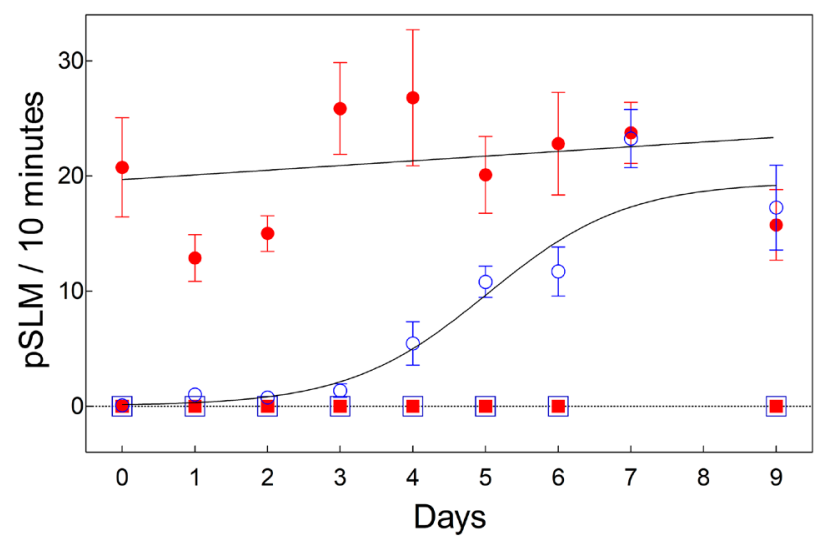

- Intact plus $1 \mathrm{mM}$ Cytisine $\quad$ No Cytisine (APW Control Intact)

- Regenerating plus $1 \mathrm{mM}$ Cytisine $\square$ No Cytisine (APW Control Regenerating)

Fig. 3. Cytisine (1 mM)-induced seizure-like movements in intact and regenerating planarians over a period of nine days. $N=4-11$ worms per symbol for the cytisine-exposed planarians), $N=4$ for controls (APWexposed planarians). Intact planarians exposed to cytisine displayed a constant response independent of the day of the experiment (Slope not different from $0 ; p=0.499$ ). The cytisine-exposed intact and regenerating planarian groups were significantly different from each other $(p<0.001$ by 2-way ANOVA). Planarians gradually recovered their ability to react to cytisine as their heads regenerated. The error bars represent the standard error of the mean. Whenever error bars are not showing it means that they are smaller than the symbol size.

\section{Cytisine, ethanol and pSLMs}

Fig. 2 shows that both cytisine and ethanol induce seizure-like movements in intact but not decapitated planarians in a concentration-dependent manner. However, ethanol displayed significant lesser potency to induce pSLMs, since even at concentrations between 300-400 mM ethanol only induced about $6 \pm 2$ pSLMs over a period of ten minutes, in contrast to the $18 \pm 8 \mathrm{pSLMs} / 10$ minutes induced by our reference cytisine concentration $(1 \mathrm{mM}$; $\mathrm{p}$ $=0.002$, unpaired t-test). These $1 \mathrm{mM}$ cytisine-induced pSLMs are not significantly different from the value for $1 \mathrm{mM}$ cytisine shown in Fig. 1 (26.0 \pm 3.0 pSLMs/10 minutes; $p=0.160$; unpaired t-test). Based on this information, we chose a standard concentration of $1 \mathrm{mM}$ cytisine to conduct the rest of our experiments.

\section{Seizure-like movements in intact and regenerating planarians induced by $1 \mathrm{mM}$ cytisine}

Fig. 3 illustrates that intact planarians react to $1 \mathrm{mM}$ cytisine in a constant manner over a period of nine days, as indicated by the slope of the line of pSLMs/10 minutes vs days, which was not different from 0 ( $p=0.499$, F-test); the average $1 \mathrm{mM}$ cytisineinduced pSLMs per ten minutes from days 0 to 9 was $20.4 \pm 1.7$, consistent with the values observed for $1 \mathrm{mM}$ cytisine under the same conditions in Figs. 1 and 2. In contrast, regenerating planarians began displaying cytisine-induced pSLMs by day 4 , which correlated closely with morphological observations of planarian brain regeneration obtained by a research group that worked on the planarian Schmidtea mediterranea (Fraguas et al., 2012). In our study, regenerating planarians recovered their full sensitivity to cytisine treatment by day 7 (Fig. 3). Intact or decapitated worms exposed to artificial pond water (APW) alone did not display SLMs (Fig. 3, as indicated). 


\section{Ethanol concentration}

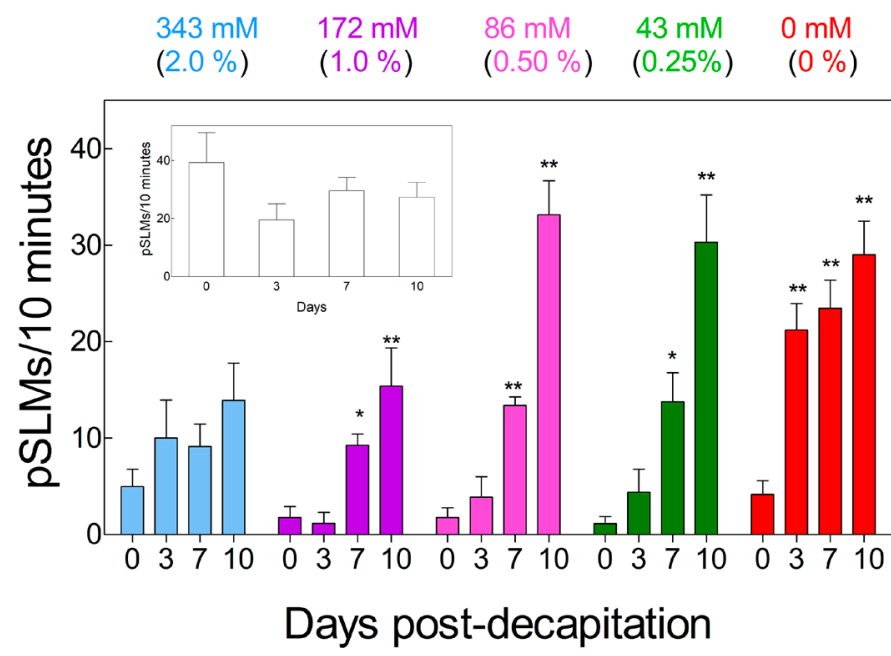

Fig. 4. Ethanol delays the onset of planarian brain regeneration in a concentration-dependent manner. $N=7-13$ worms per bar. The error bars represent the standard error of the mean. Any symbols above the bars represent statistically significant $p$-values obtained through unpaired $t$-tests against day 0 within its own group $\left({ }^{*} p<0.01 ;{ }^{* *} p<0.001\right)$. Ethanol treatment significantly differs between groups and from the control group 10 mMethanol; byTwo way ANOVA, seeTable 2). (Inset) Following an identical protocol as in the main figure, intact planarians exposed to $1 \mathrm{mM}$ cytisine displayed a constant response independent of the day of the experiment. The average pSLM numbers for days 3, 7, and 10 were not significantly different from the pSLM values at day 0 by unpaired $t$-tests $(p$-values = $0.14,0.51$, and 0.53 respectively). $N=9-13$ worms per bar. The error bars represent the standard error of the mean.

\section{Ethanol delays the onset of regeneration in regenerating planarians in a concentration-dependent manner}

As in Fig. 3, the inset in Fig. 4 shows that there is no difference in the response of intact planarians to $1 \mathrm{mM}$ cytisine exposure as a function of days; the average $1 \mathrm{mM}$ cytisine-induced pSLMs per ten minutes was $28.9 \pm 4.1$, again, consistent with the values shown in Figs. 1, 2, and 3. In contrast, Fig. 4 shows that regenerating planarians exposed to various concentrations of ethanol displayed slower regeneration rates. Their regeneration rate was delayed proportionally to the ethanol concentration (two-way ANOVA, Table 2). In fact, the worms exposed to the two highest ethanol concentrations (343 and $172 \mathrm{mM} ; 2$ and $1 \%$ respectively) never recovered their full sensitivity to the exposure of $1 \mathrm{mM}$ cytisine to control levels up to day 10 post-decapitation, while worms exposed to either 86 or $43 \mathrm{mM}$ ( 0.5 and $0.25 \%$ respectively) did recover their full sensitivity to cytisine exposure, even though their recovery was delayed compared to control worms (Fig. 4).

\section{Discussion}

\section{Ethanol effects on planarian behavior}

Ethanol has been reported to induce a variety of behavioral effects on several planarian species. One of the earliest published examples of these effects is immobilization, studied in the planarian Schmidtea mediterranea. In this planarian species, exposure to $3 \%$ ethanol (approximately $500 \mathrm{mM}$ ) for 1 hour, immobilized planarians for the purpose of performing live imaging studies (Stevenson and Beane, 2010). At this concentration and exposure time, ethanol did not show any effect on regeneration in S. mediterranea (Stevenson and Beane, 2010). Other reported effects of ethanol (at concentrations lower than $500 \mathrm{mM}$ ) on planarian behavior include decreased motility, as well as an increase in negative phototaxis behavior (Byrne, 2018; Ireland et al., 2020). In agreement with the aforementioned works, data from our laboratory indicate that ethanol slows down and eventually immobilizes the planarian $G$. tigrina in a concentration dependent manner (DeMichele, 2018).

Interestingly, in $S$. mediterranea, ethanol exposure induces the expression of a "drunken" phenotype, characterized by atypical gliding and "scrunching"; this latter behavior was found to be modulated by a specific potassium channel (Cochet-Escartin et al., 2016). In the planarian Girardia dorotocephala, ethanol displayed environmental place conditioning, pSLMs, and pharmacological synergism with cocaine, but not with nicotine (Tallarida et al., 2014). In G. dorotocephala, ethanol also seemed to induce anxiolytic-like effects (Zewde et al., 2018) and abstinence-induced withdrawal (Nayak et al., 2016).

Our work explored the effect of various ethanol concentrations using the recovery of sensitivity to cytisine exposure observed as the expression of pSLMs. We interpreted this recovery as an indicator of brain regeneration. Our results are consistent with results from another laboratory (Lowe et al., 2015) where $1 \%$ ethanol delayed the reacquisition of negative phototropic behavior of decapitated S. mediterranea. In full agreement with our experiments, Lowe et al., 2015) reported that decapitated planarians not exposed to ethanol began to recover their negative phototrophic behavior at day 4 post-decapitation while $1 \%$ ethanol delayed the onset of the recovery of this behavior, indicating brain regeneration. In these experiments, ethanol-exposed planarians began to recover their negative phototrophic behavior at day 6 on average.

\section{Cytisine}

Based on previous work from our laboratory (Pagán et al., 2013) we knew that nicotine was able to induce SLMs in decapitated planarians, while cocaine did not. We replicated these results in this work (please see Fig. 1). These results implied that the molecular targets for nicotine were distributed throughout the planarian body while the molecular targets of cocaine are specifically localized in the planarian head, likely at the level of the brain. Furthermore, previous results from our group (Pagán et al., 2013) showed that regenerating planarians gradually displayed cocaine-induced SLMs presumably as their brains were being reconstituted, suggesting a method to assess the planarian regenerative process by observing the recovery of SLMs behavior upon brain regeneration. We found

\section{TABLE 2}

\section{P-VALUES (TWO-WAY ANOVA) COMPARISON BETWEEN ETHANOL TREATMENTS (FROM Fig. 4)}

\begin{tabular}{lccccc}
$\begin{array}{l}\text { Comparison between groups } \\
\text { Ethanol }(\mathrm{mM})\end{array}$ & $\mathbf{0}$ & $\mathbf{3 4 3}$ & $\mathbf{1 7 2}$ & $\mathbf{8 6}$ & $\mathbf{4 3}$ \\
\hline $\mathbf{0}$ & - & 0.013 & 0.011 & 0.0007 & 0.015 \\
$\mathbf{3 4 3}$ & - & - & - & - & - \\
$\mathbf{1 7 2}$ & - & 0.284 & - & - & - \\
$\mathbf{8 6}$ & - & 0.0001 & 0.0007 & - & - \\
$\mathbf{4 3}$ & - & 0.003 & 0.035 & 0.914 & - \\
\hline
\end{tabular}


that the cholinergic compound cytisine, a neurotoxin isolated from the Laburnum plant, induced a robust pSLM response in intact planarians while showing no such effect in decapitated planarians (Fig. 1), suggesting that cytisine's receptors sites in planarians are located in the head region, most likely in the brain.

Interestingly, our data also suggests that there are at least two populations of NMDA receptor targets in G. tigrina; based on the approximately $50 \%$ reduction of pSLMs in decapitated worms. Our hypotheses about the possible localization of the binding sites for cocaine, nicotine, cytisine, and NMDA in the planarian nervous system are consistent with an operational receptor model, which preliminarily assumes the existence of specific targets for a drug based solely on any observed physiological/behavioral effects in the absence of molecular data (Black and Leff, 1983, 1985, 2010; Leff et al., 1985, 1990).

Cytisine has been used with a moderate level of success as a tobacco cessation therapy; its best described effect is as a partial agonist in neuronal nicotinic cholinergic receptors in the vertebrate brains (Beard et al., 2016; Etter, 2008; Gomez-Coronado et al., 2018; Walker et al., 2016). In vertebrates, the location of neuronal cholinergic receptors is mostly limited to the central nervous system (Bertrand and Terry, 2018; Zoli et al., 2015, 2018). This fact, combined with our results, is consistent with the idea that the planarian nervous system parallels vertebrate nervous systems (Pagán et al., 2013; Pagán, 2014, 2017, 2019; Sarnat and Netsky 1985, 2002).

Fig. 2 shows that the induction of pSLMs by cytisine is concentration-dependent, further reinforcing the notion of a specific receptor site in intact planarians. Cytisine was unable to induce pSLMs in decapitated planarians up to a concentration of $3 \mathrm{mM}$ (Fig. 2). In contrast, ethanol was able to induce pSLMs at much higher concentrations than cytisine. For example, ethanol induced about 6 pSLMs in ten minutes at concentrations between 300 and $400 \mathrm{mM}$ in intact planarians; and like cytisine, no seizure-like movements were observed in decapitated worms (Fig. 2). It is unlikely that ethanol contributed to any observed pSLMs in our experiments, since all the worms used in our experiments were washed in $1 \mathrm{~mL}$ APW (see methods); this wash was discarded prior to exposing the worms with APW containing $1 \mathrm{mM}$ cytisine.

The rate of brain regeneration that we observed was consistent with results from other research groups in various planarians species (Reviewed in Birkholz et al., 2019; Brown and Pearson, 2017, Cebrià 2007; Cebrià et al., 2018; Fraguas et al., 2012; Inoue et al., 2004; Ivankovic et al., 2019; Ross et al., 2017). Our experiments show that intact planarians, as expected, displayed a constant response to $1 \mathrm{mM}$ cytisine exposure over a period of nine days, in contrast to decapitated planarians, which did not significantly respond to this cytisine treatment until day four, when they began to display pSLMs, indicating a gradual recovery of function, which was complete by day 9 (Fig. 3). The observed recovery in our experiments is consistent with morphological observations of the brain of different planarian species by other groups showing that the brain hemispheres began to recover their connectivity by approximately day four post-decapitation (Cebrià, 2007; Fraguas et al., 2012).

In Fig. 4 we show that decapitated planarians exposed to ethanol display a delay in their recovery of cytisine sensitivity, which can be interpreted as a delay in the process of brain regeneration. Planarians exposed to 0.25 and $0.50 \%$ ethanol recovered their full brain functionality (as interpreted from the observed recovery of full sensitivity to $1 \mathrm{mM}$ cytisine treatment), while planarians exposed to 1 or $2 \%$ ethanol did not. Overall, these data suggests that our method has the potential to help identify substances influencing planarian brain regeneration based on the recovery of cytisine-induced pSLMs. Moreover, our method has the advantage that it can be easily modified to adapt it for various experimental needs. For example, instead of following regeneration over a ten day period, a specific day post-decapitation (say, 5 days) could be chosen as a reference endpoint to observe whether a specific substance delays or enhances regeneration by quantifying any pSLMs induced by $1 \mathrm{mM}$ cytisine. This is only one of the possible modifications of our method that can be implemented.

\section{Challenges and future work}

Despite the potential usefulness of the cytisine method, there are certain disadvantages that must be addressed. For example, there is a distinct possibility that there are substances influencing planarian brain regeneration that also induce pSLMs by themselves, possibly confounding the interpretation of results or that antagonize cytisine's ability to induce pSLMs. The obvious compounds in this regard are other cholinergic agents, a possibility that we intend to explore through a systematic screening with cholinergic agents with different specificities, particularly cholinergic antagonists. In essence, we intend to perform a pharmacological dissection to look for cytisine antagonists, which may not be limited to cholinergic agents. For example, in vertebrate organisms the cholinergic and dopaminergic neurotransmitter systems are closely related. This relationship is being explored in the context of Parkinson's Disease (Rizzi and Tan, 2017). Interestingly, the study of acetylcholine/dopamine interaction has also been proposed in planarians (Buttarelli et al., 2000; Carolei et al., 1975). This possibility of cross-interaction of compounds that might confound any cytisine results can be easily prevented by changing the experimental design. For example, by exposing decapitated planarians to a candidate substance for say, three days, then removing the tested substance, allowing the planarians to regenerate normally for two days, and then test for cytisine-induced pSLMs. We are designing alternative protocols in our laboratory as suitable modifications of this method. Another possible limitation of our method is whether cytisine affects planarian regeneration by itself. We are also planning experiments to address this possibility. An exciting possible set of experiments that we intend to pursue is to explore any cytisine effects on planarian heads as opposed to their decapitated bodies; amputated planarian heads display significant motility that can be quantified (Please see Supplementary video 2); we can also follow their body regeneration in light of their sensitivity to cytisine and perform pharmacological dissection studies as outlined above. Additional future work in our laboratory will include immunohistochemical studies to assess and compare the extent of planarian brain reconstitution with the recovery of sensitivity to cytisine. Another interesting aspect of our results that can be explored is the nature of the putative distinct populations of NMDA receptors that we seem to have identified in G. tigrina.

The impressive regenerative abilities of planarians offer unique insights into the regain of the neuronal structural reorganization that is necessary to recover the expression of normal behavior after injury. Our results indicate that the recovery of cytisine sensitivity in regenerating planarians is an innovative, inexpensive, and use- 


\section{General Planarian Stock}

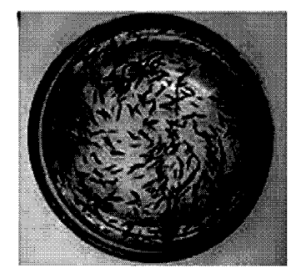

\section{Set aside $\mathbf{4 8}$ worms and decapitate them (Group 1) Day 0: Record pSLMs induced by either APW} (4 worms) or $1 \mathrm{mM}$ cytisine (4 worms).

\section{\. \\ Discard worms. \\ Go back to Groups 1 and 2 . Repeat for days $1,2,3$, etc.}

Fig. 5. Experimental setup used to assess the recovery of cytisine sensitivity upon head regeneration in decapitated worms (see text).

ful method to assess the effect of exogenous substances on the observed brain regeneration in this experimental organism. As a validation of our method, our results indicate that ethanol slows down the rate of planarian brain regeneration in a concentrationdependent manner, in full agreement with data from other research groups using alternate behavioral methods in a different planarian species (Lowe et al., 2015). Therefore, here we establish cytisineinduced pSLMs as an indicator of brain regeneration in our experimental organism, providing a general method to assess the effect of exogenous compounds on this process. This method will likely contribute to the identification of substances capable of delaying, and perhaps even enhancing, planarian brain regeneration. Our work represents an additional tool that will likely prove useful on the integration of the fields of pharmacology, neuroscience, and regeneration/developmental biology, with planarians as a leading model organism.

\section{Materials and Methods}

\section{Data analysis}

All graphs and statistical procedures were done using the Prism software package (GraphPad Inc., La Jolla, CA, USA). Planarians (Girardia tigrina) were obtained from Ward's (Rochester, NY). The water in which the worms were shipped was replaced with artificial pond water (APW: $\mathrm{NaCl}, 6 \mathrm{mM} ; \mathrm{NaHCO}_{3}, 0.1 \mathrm{mM} ; \mathrm{CaCl}_{2}, 0.6 \mathrm{mM}$ ) immediately upon arrival, and the animals were allowed to acclimate to the laboratory conditions for about 24 hours before being used. All experiments were performed in APW at room temperature. Planarians between $1-1.5 \mathrm{~cm}$ were selected for the experiments. Cytisine was purchased from Tocris (Ellisville, MO). General laboratory materials and chemicals were purchased from Fisher Scientific (Suwanee, GA).

\section{Induction of pSLMs}

In all tests, the induction of pSLMs by cytisine was measured by exposing a worm to approximately $1 \mathrm{~mL}$ of APW, followed by the removal of the APW (wash) and placing the worm inside the well of a ceramic plate (Supplementary Video 1). Then the relevant cytisine concentration was added to the well and any pSLMs were visually counted for a period of ten minutes. For an illustration of what pSLMs look like, please refer to Supplementary Video 1. All experiments were performed by at least two observers, and after counting, the worms were humanely euthanized and discarded by adding $2 \%$ hydrochloric acid to the experimental solution.

\section{Candidate compounds to study pSMLs in planarians}

We chose substances that at a concentration of $1 \mathrm{mM}$ induced at least $15 \mathrm{pSLMs}$ in intact planarians over a ten-minute period, following our previous results using cocaine as a reference compound (Pagán et al., 2013). Upon finding such a compound, we exposed decapitated planarians to 1 $\mathrm{mM}$ of the candidate compound. If the planarian body did not react to this exposure, we chose the compound for further study.

\section{Recovery of behavioral function upon brain regeneration}

This procedure was first described in Pagán et al., (2013), and summarized in Fig. 5. Briefly, two sets of planarians, 48 worms each, were placed in separate containers in APW. One of the groups was designated "Planarian Stock 1" (PS1), and each planarian was decapitated as shown in Fig. 2. The second group, "Planarian Stock 2" (PS2) was left intact. The APW was changed every day. Starting at the decapitation date (Day 0) eight planarians of each set were exposed to either APW or $1 \mathrm{mM}$ cytisine and counted as described above. All experiments were done at room temperature and the worms were not fed at any point during the experiments. The procedure was repeated in subsequent days by going back to the PS1 and PS2 as described in Fig. 5 as well as in the "Results and Discussion" section. In this way, the gradual recovery of the pSLM response was observed as a function of days after decapitation; this is the method by through we obtained the data to construct Fig. 3. After counting, the worms were euthanized and discarded as described above.

\section{Effect of ethanol on the recovery of cytisine sensitivity of regenerating planarians}

Five sets of four 12-well polypropylene plates were washed with APW twice and the wash discarded. Each set was assigned to contain control worms (exposed to APW) or experimental worms (exposed to $0.25,0.50$, 1.0 , or $2.0 \%$ ethanol in APW). Each well contained only one decapitated planarian. Each of the four plates represented the days of exposure $(0$, 3,7 , or 10 days). In each of the designated days, the appropriate plate was set aside, and each individual worm was tested for the expression of pSLMs induced by $1 \mathrm{mM}$ cytisine as described in the "Induction of pSLMs" section above. The data was processed and graphed as described (Fig. 4).

\section{Acknowledgments}

We thank Dr. Joshua Auld of the Department of Biology at West Chester University and Dr. Rachel Roberts-Galbraith from the Department of Cellular Biology, University of Georgia, for useful suggestions. We are very grateful for the financial support from the Department of Biology, West Chester University, and for a Research in Science and Mathematics (RIMS) Grant from the College of Sciences and Mathematics, West Chester University. We gratefully acknowledge the financial contribution from the National Institutes of Health (NIH; R03DA026518, to O.R.P.). We declare no conflict of interests.

\section{References}

BACH, D. J., TENAGLIA, M., BAKER, D. L., DEATS, S., MONTGOMERY, E. and PAGÁN, O. R. (2016). Cotinine antagonizes the behavioral effects of nicotine exposure in the planarian Girardia tigrina. Neurosci Lett 632: 204-208.

BEARD, E., SHAHAB, L., CUMMINGS, D. M., MICHIE, S. and WEST, R. (2016). New Pharmacological Agents to Aid Smoking Cessation and Tobacco Harm Reduction: What Has Been Investigated, and What Is in the Pipeline? CNS Drugs30: 951-983. 
BERTRAND, D. and TERRY, A. V. (2018). The wonderland of neuronal nicotinic acetylcholine receptors. Biochem Pharmacol 151:214-225.

BEZERRA DA SILVA, C., POTT, A., ELIFIO-ESPOSITO, S., DALARMI, L., FIALHO DO NASCIMENTO, K., MOURABURCI, L., DE OLIVEIRA, M., DE FÁTIMA GASPARI DIAS, J., WARUMBY ZANIN, S. M., GOMES MIGUEL, O. and DALLARMI MIGUEL, M. (2016). Effect of Donepezil, Tacrine, Galantamine and Rivastigmine on Acetylcholinesterase Inhibition in Dugesia tigrina. Molecules 21: 53.

BIRKHOLZ, T. R., VAN HUIZEN, A. V. and BEANE, W. S. (2019). Staying in shape: Planarians as a model for understanding regenerative morphology. Semin Cell Dev Biol 87: 105-115

BLACK, J. W. and LEFF, P. (1983). Operational models of pharmacological agonism. Proc R Soc Lond B Biol Sci 220: 141-162.

BLACK, J. W., LEFF, P., SHANKLEY, N. P. and WOOD, J. (1985). An operational model of pharmacological agonism: the effect of $E /[A]$ curve shape on agonist dissociation constant estimation. Br J Pharmacol 84: 561-571.

BLACK, J. W., LEFF, P., SHANKLEY, N. P. and WOOD, J. (2010). An operational model of pharmacological agonism: the effect of $E /[A]$ curve shape on agonist dissociation constant estimation. 1985. Br J Pharmacol 160: S54-S64.

BROWN, D. D. R. and PEARSON, B. J. (2017). A Brain Unfixed: Unlimited Neurogenesis and Regeneration of the Adult Planarian Nervous System. Front Neurosci 11: 289.

BUTTARELLI, F. R., PELLICANO, C. and PONTIERI, F. E. (2008). Neuropharmacology and behavior in planarians: translations to mammals. Comp Biochem Physiol C Toxicol Pharmacol 147: 399-408.

BUTTARELLI, F. R., PONTIERI, F. E., MARGOTTA, V. and PALLADINI, G. (2000). Acetylcholine/dopamine interaction in planaria. Comp Biochem Physiol C Toxicol Pharmacol 125: 225-231.

BYRNE, T. (2018). Effects of ethanol on negative phototaxis and motility in brown planarians (Dugesia tigrina). Neurosci Lett 685: 102-108.

CAROLEI, A., MARGOTTA, V. and PALLADINI, G. (1975). Proposal of a new model with dopaminergic-cholinergic interactions for neuropharmacological investigations. Neuropsychobiology 1: 355-364.

CEBRIÀ, F. (2007). Regenerating the central nervous system: how easy for planarians! Dev Genes Evol 217: 733-748.

CEBRIÀ, F. (2008). Organization of the nervous system in the model planarian Schmidtea mediterranea: an immunocytochemical study. Neurosci Res61:375-384.

CEBRIÀ, F. (2019). Planarians are here to stay and to teach us a lot on regeneration. Semin Cell Dev Biol 87: 1-2

CEBRIÀ, F., ADELL, T. and SALÓ, E. (2018). Rebuilding a planarian: from early signaling to final shape. Int $J$ Dev Biol 62: 537-550.

CEBRIÀ, F., KUDOME, T., NAKAZAWA, M., MINETA, K., IKEO, K., GOJOBORI, T. and AGATA, K. (2002a). The expression of neural-specific genes reveals the structural and molecular complexity of the planarian central nervous system. Mech Dev 116: 199-204.

CEBRIÀ F, NAKAZAWA M, MINETA K, IKEO K, GOJOBORI T, AGATA K. (2002b). Dissecting planarian central nervous system regeneration by the expression of neural-specific genes. Dev Growth Differ 44: 135-46.

COCHET-ESCARTIN, O., CARTER, J. A., CHAKRAVERTI-WUERTHWEIN, M., SINHA, J. and COLLINS, E. M. (2016). Slo1 regulates ethanol-induced scrunching in freshwater planarians. Phys Biol 13: 055001.

DEMICHELEG. (2018). Effects of Ethanol on Dugesia tigrina's Behaviorand Regeneration Time. Master's Thesis. West Chester University of Pennsylvania. West Chester.

ETTER, J. F., LUKAS, R. J., BENOWITZ, N. L., WEST, R. and DRESLER, C. M. (2008). Cytisine for smoking cessation: a research agenda. Drug Alcohol Depend 92: 3-8.

FRAGUAS, S., BARBERÁN, S., IBARRA, B., STÖGER, L. and CEBRIÀ, F. (2012). Regeneration of neuronal cell types in Schmidtea mediterranea: an immunohistochemical and expression study. Int J Dev Biol 56: 143-153.

GENTILE, L., CEBRIÀ, F. and BARTSCHERER, K. (2011). The planarian flatworm: an in vivo model for stem cell biology and nervous system regeneration. Dis Model Mech 4: 12-19.

GÓMEZ-CORONADO, N., WALKER, A. J., BERK, M. and DODD, S. (2018). Current and Emerging Pharmacotherapies for Cessation of Tobacco Smoking. Pharmacotherapy 38: 235-258.

HAGSTROM, D., COCHET-ESCARTIN, O. and COLLINS, E. M. (2016). Planarian brain regeneration as a model system for developmental neurotoxicology. Regeneration (Oxf) 3: 65-77.
HAGSTROM, D., COCHET-ESCARTIN, O., ZHANG, S., KHUU, C. and COLLINS, E. M. (2015). Freshwater Planarians as an Alternative Animal Model for Neurotoxicology. Toxicol Sci 147: 270-285.

HAGSTROM, D., TRUONG, L., ZHANG, S., TANGUAY, R. and COLLINS, E. S. (2019) Comparative Analysis of Zebrafish and Planarian Model Systems for Developmental Neurotoxicity Screens Using an 87-Compound Library. Toxicol Sci 167: 15-25.

INOUE, T., KUMAMOTO, H., OKAMOTO, K., UMESONO, Y., SAKAI, M., SÁNCHEZ ALVARADO, A. and AGATA, K. (2004). Morphological and functional recovery of the planarian photosensing system during head regeneration. Zoolog Sci21:275-283.

IRELAND, D., BOCHENEK, V., CHAIKEN, D., RABELER, C., ONOE, S., SONI, A and COLLINS, E. S. (2020). Dugesia japonica is the best suited of three planarian species for high-throughput toxicology screening. Chemosphere 253: 126718.

IVANKOVIC, M., HANECKOVA, R., THOMMEN, A., GROHME, M. A., VILA-FARRÉ, M., WERNER, S. and RINK, J. C. (2019). Model systems for regeneration: planarians. Development 146(17):dev167684. doi: 10.1242/dev.167684.

LEFF, P., MARTIN, G. R. and MORSE, J. M. (1985). Application of the operational model of agonism to establish conditions when functional antagonism may be used to estimate agonist dissociation constants. Br J Pharmacol 85: 655-663.

LEFF, P., PRENTICE, D. J., GILES, H., MARTIN, G. R. and WOOD, J. (1990). Estimation of agonist affinity and efficacy by direct, operational model-fitting. $J$ Pharmacol Methods 23: 225-237.

LI, Q., YANG, H. and ZHONG, T. P. (2015). Regeneration across metazoan phylogeny: lessons from model organisms. J Genet Genomics 42: 57-70.

LOWE, J. R., MAHOOL, T. D. and STAEHLE, M. M. (2015). Ethanol exposure induces a delay in the reacquisition of function during head regeneration in Schmidtea mediterranea. Neurotoxicol Teratol 48: 28-32.

MINETA, K., NAKAZAWA, M., CEBRIA, F., IKEO, K., AGATA, K. and GOJOBORI, T (2003). Origin and evolutionary process of the CNS elucidated by comparative genomics analysis of planarian ESTs. Proc Natl Acad Sci USA 100: 7666-7671.

NAKAZAWA, M., CEBRIÀ, F., MINETA, K., IKEO, K., AGATA, K. and GOJOBORI, T. (2003). Search for the evolutionary origin of a brain: planarian brain characterized by microarray. Mol Biol Evol 20: 784-791.

NAYAK, S., ROBERTS, A., BIRES, K., TALLARIDA, C. S., KIM, E., WU, M. and RAWLS, S. M. (2016). Benzodiazepine inhibits anxiogenic-like response in cocaine or ethanol withdrawn planarians. Behav Pharmacol 27: 556-558

OWLARN, S. and BARTSCHERER, K. (2016). Go ahead, grow a head! A planarian's guide to anterior regeneration. Regeneration (Oxf) 3: 139-155.

PAGÁN O. R. (2014). The first brain: the neuroscience of planarians. Oxford University Press, New York.

PAGÁN, O. R. (2017). Planaria: an animal model that integrates development, regeneration and pharmacology. Int J Dev Biol 61: 519-529.

PAGÁN, O. R. (2019). The brain: a concept in flux. Philos Trans $R$ Soc Lond B Biol Sci 374: 20180383.

PAGÁN, O. R., BAKER, D., DEATS, S., MONTGOMERY, E., TENAGLIA, M., RANDOLPH, C., KOTTURU, D., TALLARIDA, C., BACH, D., WILK, G., RAWLS, S. and RAFFA, R. B. (2012). Planarians in pharmacology: parthenolide is a specific behavioral antagonist of cocaine in the planarian Girardia tigrina. Int J Dev Biol 56: 193-196.

PAGÁN, O. R., DEATS, S., BAKER, D., MONTGOMERY, E., WILK, G., TENAGLIA, M. and SEMON, J. (2013). Planarians require an intact brain to behaviorally react to cocaine, but not to react to nicotine. Neuroscience 246: 265-270.

PAGÁN, O. R., MONTGOMERY, E., DEATS, S., BACH, D. and BAKER, D. (2015). Evidence of Nicotine-Induced, Curare-Insensitive, Behavior in Planarians. Neurochem Res 40: 2087-2090.

PAGÁN, O. R., ROWLANDS, A. L., AZAM, M., URBAN, K. R., BIDJA, A. H., ROY, D. M., FEENEY, R. B. and AFSHARI, L. K. (2008). Reversal of cocaine-induced planarian behavior by parthenolide and related sesquiterpene lactones. Pharmacol Biochem Behav 89: 160-170.

PALLADINI, G., RUGGERI, S., STOCCHI, F., DE PANDIS, M. F., VENTURINI, G. and MARGOTTA, V. (1996). A pharmacological study of cocaine activity in planaria Comp Biochem Physiol C Pharmacol Toxicol Endocrinol 115: 41-45.

PELLETTIERI, J. (2019). Regenerative tissue remodeling in planarians - The mysteries of morphallaxis. Semin Cell Dev Biol 87: 13-21.

POIRIER, L., GHIGO, É., DAUDÉ, D. and CHABRIĖRE, É. 2019. [Planarian, an emerging animal model for toxicology studies]. Med Sci (Paris) 35: 544-548. 
RAFFA RB, RAWLS SM (Eds) (2008). Planaria: A Model for Drug Action and Abuse. Molecular Biology Intelligence Unit. Landes Bioscience. Austin.

RAMAKRISHNAN, L., DALHOFF, Z., FETTIG, S. L., EGGERICHS, M. R., NELSON, B. E., SHRESTHA, B., ELSHIKH, A. H. and KARKI, P. (2013). Riluzole attenuates the effects of chemoconvulsants acting on glutamatergic and GABAergic neurotransmission in the planarian Dugesia tigrina. Eur J Pharmacol 718: 493-501.

RAMAKRISHNAN, L. and DESAER, C. (2011). Carbamazepine inhibits distinct chemoconvulsant-induced seizure-like activity in Dugesia tigrina. Pharmacol Biochem Behav 99: 665-670.

RAMOZ, L., LODI, S., BHATT, P., REITZ, A. B., TALLARIDA, C., TALLARIDA, R. J., RAFFA, R. B. and RAWLS, S. M. (2012). Mephedrone ("bath salt") pharmacology: insights from invertebrates. Neuroscience 208: 79-84.

RAWLS, S. M., KARACA, F., MADHANI, I., BHOJANI, V., MARTINEZ, R. L., ABOUGHARBIA, M. and RAFFA, R. B. 2010. $\beta$-lactamase inhibitors display anti-seizure properties in an invertebrate assay. Neuroscience 169: 1800-1804.

RAWLS, S. M., PATIL, T., TALLARIDA, C. S., BARON, S., KIM, M., SONG, K., WARD, S. and RAFFA, R. B. (2011). Nicotine behavioral pharmacology: clues from planarians. Drug Alcohol Depend 118: 274-279.

RAWLS, S. M., THOMAS, T., ADEOLA, M., PATIL, T., RAYMONDI, N., POLES, A., LOO, M. and RAFFA, R. B. (2009). Topiramate antagonizes NMDA- and AMPAinduced seizure-like activity in planarians. Pharmacol Biochem Behav93:363-367.

RIBEIRO, P., EL-SHEHABI, F. and PATOCKA, N. (2005). Classical transmitters and their receptors in flatworms. Parasitology 131 Suppl:S19-40.

RIZZI, G. and TAN, K. R. (2017). Dopamine and Acetylcholine, a Circuit Point of View in Parkinson's Disease. Front Neural Circuits 11: 110.

ROBERTS-GALBRAITH, R. H., BRUBACHER, J. L. and NEWMARK, P. A. (2016). A functional genomics screen in planarians reveals regulators of whole-brain regeneration. Elife 5: e17002.

ROBERTS-GALBRAITH, R. H. and NEWMARK, P. A. (2015). On the organ trail: insights into organ regeneration in the planarian. Curr Opin Genet Dev32: 37-46.
ROSS, K. G., CURRIE, K. W., PEARSON, B. J. and ZAYAS, R. M. (2017). Nervous system development and regeneration in freshwater planarians. Wiley Interdiscip Rev Dev Biol 6: e266.

SARNAT, H. B. and NETSKY, M. G. (1985). The brain of the planarian as the ancestor of the human brain. Can J Neurol Sci 12: 296-302.

SARNAT, H. B. and NETSKY, M. G. (2002). When does a ganglion become a brain? Evolutionary origin of the central nervous system. Semin Pediatr Neurol9:240-253.

STEVENSON, C. G. and BEANE, W. S. (2010). A low percent ethanol method for immobilizing planarians. PLoS One 5:e15310.

TALLARIDA, C. S., BIRES, K., AVERSHAL, J., TALLARIDA, R. J., SEO, S. and RAWLS, S. M. (2014). Ethanol and cocaine: environmental place conditioning, stereotypy, and synergism in planarians. Alcohol 48: 579-586.

UMESONO Y, AGATA K. (2009). Evolution and regeneration of the planarian central nervous system. Dev Growth Differ 51: 185-95.

UMESONO, Y., TASAKI, J., NISHIMURA, K., INOUE, T. and AGATA, K. (2011) Regeneration in an evolutionarily primitive brain--the planarian Dugesia japonica model. Eur J Neurosci 34: 863-869.

WU, J. P. and LI, M. H. (2018). The use of freshwater planarians in environmental toxicology studies: Advantages and potential. Ecotoxicol Environ Saf 161: 45-56.

ZEWDE, A. M., YU, F., NAYAK, S., TALLARIDA, C., REITZ, A. B., KIRBY, L. G. and RAWLS, S. M. (2018). PLDT (planarian light/dark test): an invertebrate assay to quantify defensive responding and study anxiety-like effects. J Neurosci Methods 293: 284-288.

ZHANG, S., HAGSTROM, D., HAYES, P., GRAHAM, A. and COLLINS, E. S. (2019). Multi-Behavioral Endpoint Testing of an 87-Chemical Compound Library in Freshwater Planarians. Toxicol Sci 167: 26-44.

ZOLI, M., PISTILLO, F. and GOTTI, C. (2015). Diversity of native nicotinic receptor subtypes in mammalian brain. Neuropharmacology 96: 302-311.

ZOLI, M., PUCCI, S., VILELLA, A. and GOTTI, C. (2018). Neuronal and Extraneurona Nicotinic Acetylcholine Receptors. Curr Neuropharmacol 16: 338-349. 


\section{Further Related Reading, published previously in the Int. J. Dev. Biol.}

Smed-egfr-4 is required for planarian eye regeneration

Elena Emili, Macià Esteve Pallarès, Rafael Romero and Francesc Cebrià

Int. J. Dev. Biol. (2019) 63: 9-15

https://doi.org/10.1387/ijdb.180361fc

Rebuilding a planarian: from early signaling to final shape

Francesc Cebrià, Teresa Adell and Emili Saló

Int. J. Dev. Biol. (2018) 62: 537-550

https://doi.org/10.1387/ijdb.180042es

Myths vs. FACS: what do we know about planarian stem cell lineages?

Alyssa M. Molinaro and Bret J. Pearson

Int. J. Dev. Biol. (2018) 62: 527-535

https://doi.org/10.1387/ijdb.180066bp

Planaria: an animal model that integrates development, regeneration and pharmacology Oné R. Pagán

Int. J. Dev. Biol. (2017) 61: 519-529

https://doi.org/10.1387/ijdb.160328op

Regeneration of neuronal cell types in Schmidtea mediterranea: an immunohistochemical and expression study

Susanna Fraguas, Sara Barberán, Begoña Ibarra, Linda Stöger and Francesc Cebrià Int. J. Dev. Biol. (2012) 56: 143-153

https://doi.org/10.1387/ijdb.113428sf

\section{Small RNA pathways in Schmidtea mediterranea}

Alissa M. Resch and Dasaradhi Palakodeti

Int. J. Dev. Biol. (2012) 56: 67-74

https://doi.org/10.1387/ijdb.113436ar

Planarian embryology in the era of comparative developmental biology

José M. Martín-Durán, Francisco Monjo and Rafael Romero

Int. J. Dev. Biol. (2012) 56: 39-48

https://doi.org/10.1387/ijdb.113442jm
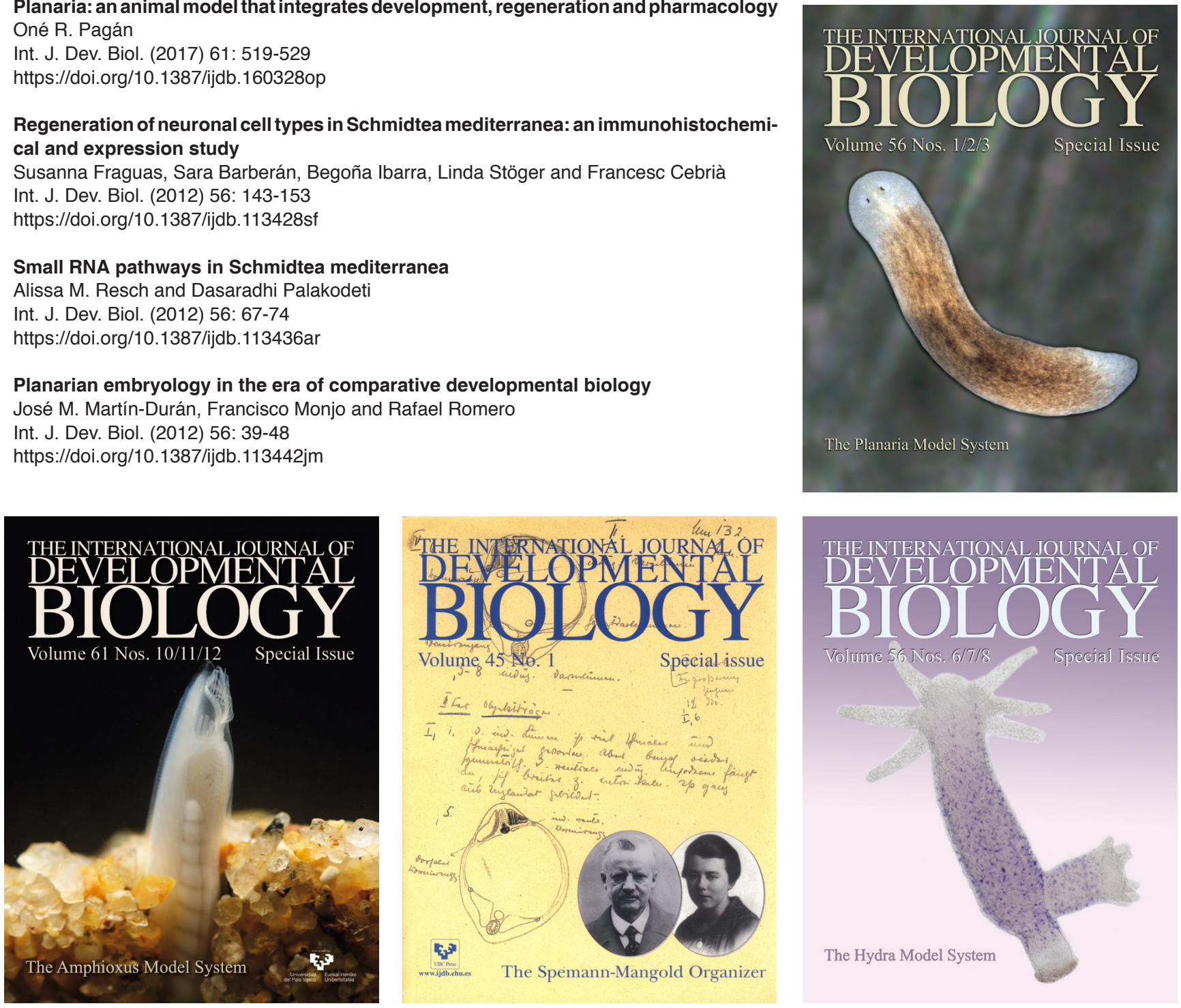